Universidad de Lima

Facultad de Comunicación

Carrera de Comunicación

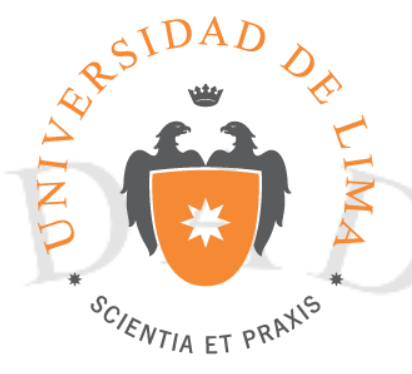

\title{
SIN PERDER EL CABLE A TIERRA: LA IDENTIDAD DEL VIAJERO Y SU INTERACCIÓN EN EL MUNDO VIRTUAL
}

Trabajo de investigación para optar la licenciatura en Comunicación

\section{CLARISA MARIA NUÑEZ - MELGAR MOLINARI}

Código 20090774

Asesora

Lilian Kanashiro Nakahodo

$$
\text { Lima - Perú }
$$

Septiembre de 2015 


\section{RESUMEN}

Estudios realizados plantean que los viajeros de estilo de vida son una comunidad no cautiva, que comparten características como la necesidad y casi adicción por moverse, así como el deseo de conocer el mundo sin ningún tipo de atadura. A su vez, se plantea que la tecnología y plataformas virtuales, encapsulan a este grupo, generándoles la necesidad de permanecer conectados durante el viaje y logrando que generen espacios dentro del mundo virtual. En el presente estudio, se encuentran más caras de este colectivo, como la relación directa con la que asocian el viaje con el escape aunque prefieran entenderlo como una búsqueda en nuevos contextos y el rechazo rotundo del grupo a ser calificados como turistas, inclinándose hacia su experiencia como una vivencia única. Por otro lado, se plantea el miedo a la desconexión, de la mano con la utilidad y carácter indispensable que tienen las plataformas virtuales en el proceso de viaje. Se puede decir que esta relación es muy útil en sus viajes pero circunstancial e ingrata. Esto se concluye, debido a que se encontró un patrón de respuesta en las treinta y tres entrevistas realizadas, formando un perfil característico del viajero y su conexión con el mundo virtual al momento del viaje. El viajero actual, se mueve por el mundo pero la desconexión no es algo que siquiera se plantee.

\section{PALABRAS CLAVES}

Interacción Cultural, Tecnología de la Información, Identidad cultural, Nomadismo. 


\section{INTRODUCCIÓN}

Plantear el perfil de un viajero de estilo de vida, resulta una tarea compleja pues cuando se menciona esta comunidad es importante desligarse de toda noción tradicional de segmentación, aquella basada en edad, género, origen, oficio o profesión. Para de esta manera poder entender a esta comunidad como heterogéneos con algo en común, que puede ser denominado el gen Wanderlust (Dobbs, 2013) o apartándonos de la teoría científica, "la pasión por los viajes"1. El viajero del siglo XXI muta y deja atrás el discurso anarquista y de exilio. El viaje se ve desde otra perspectiva mientras que la aventura e incertidumbre del mismo sigue intacta. Esta investigación tiene como principal objetivo, esclarecer el rol que juegan estas nuevas propuestas virtuales para los viajes de esta comunidad, preguntándonos si es que es posible la total desconexión. Además, entender y perfilar de manera más específica a este grupo, conociendo sus motivaciones, filosofías de vida y concepción del mismo viaje. Finalmente, cuestionar y conocer el aporte generado por los espacios virtuales de acuerdo a las necesidades del viajero. ¿Realmente se puede estar desconectado al momento del viaje o existe un cable a tierra en medio del romanticismo del viaje de larga estancia?

\section{El mundo 2.0}

Cuando hablamos del siglo XXI lo primero que viene a la mente son estas palabras: "tecnología", "globalización", "virtualidad” y sobre todo, un tipo de interacción que supera los límites físicos. Además, se podría decir que la tecnología ha logrado generar una cierta dependencia a raíz de la utilidad y necesidad detectada o para algunos escépticos, inducida. Para Manuel Castells (2001), esta noción de dependencia hacia lo tecnológico y la idea de globalización como una gran interconexión mundial; no es necesariamente consecuencia de la tecnología en las comunicaciones del siglo XXI. Mas bien menciona, que en la antigüedad, ya existía una especie de globalización por la cual las sociedades dependían en sentido económico y político de la conexión con otros lugares por medio de redes, que transcendían los límites locales. Esto de alguna manera ha sido rechazado por otros teóricos para volver este fenómeno en una consecuencia directa de los avances tecnológicos y así plantear una

\footnotetext{
${ }^{1}$ Término planteada por Kidd, tras desmitificar la idea del gen viajero. Argumentando que un solo gen no puede englobar tantas características. (Dobbs, 2013)
} 
"evolución social". Sin embargo, se sabe que toda sociedad ha sido estructurada sobre redes ya que estas cuentan con capacidad de auto reconfigurarse y adaptarse en el contexto, por lo que se cree en un cambio más que en un surgimiento.

Ahora bien, se puede decir que las tecnologías han hecho que las redes (soporte de sociedades) puedan estar interconectadas de manera rápida y sencilla, aportando inmediatez al intercambio deseado, confiando en infraestructuras virtuales que sirvan de canal y además de medio de información para esta interacción. Además, con estos avances, la brecha entre el mundo real y el mundo virtual, ha disminuido notablemente, en la búsqueda de mimetizarse y formar un mundo integrado a la nube. De esta forma, las redes tienen acceso desde la interacción privada hasta cualquier tipo expresión o actividad del ser humano.

Sin embargo, Eduardo Villanueva (2010), resalta la identidad propia de la era actual en la que impera la globalización virtual. Plantea que la tecnología y el desarrollo virtual de las redes, ha propiciado un mundo en el que la autoría ha desaparecido. Julio Cesar Mateus (2010) agrega que no solo nos referimos a una era tecnológica sino a una cultura digital. Con esto, el concepto del ciudadano cambia y se puede notar un salto en las percepciones que esta persona maneja. Desde su concepción de espacio y tiempo, hasta su interacción con las demás personas. De esta forma, ambos autores confluyen en que esta cultura trae consigo una sociedad basada en la interacción virtual. Toda persona con acceso a la nube puede crear y fruto de esta teoría son los nativos digitales y los netizens, quienes marcan un hito con la creación de contenidos gratuitos. La apertura de un mercado invisible pero prometedor, hace que tanto el campo económico como político se democratice, dejando de lado, como menciona Mateus, “debates y oposiciones ambiguas - idealismo pragmatismo, más Estado/menos Estado, pobres/ricos- que hoy, más que nunca, parecen hibridarse, extinguirse o paradójicamente coincidir". Así como en lo económico, el concepto de un creador y a la vez consumidor, cierra el carácter integrado, abierto y empoderador de particulares del último siglo.

Finalmente, ante las cualidades de esta era tecnológica, Tom Chatfield (2012) destaca aspectos positivos de la misma como la rápidez y libre acceso a una biblioteca de data interminable, pero sobre todo la opción de apertura al mundo y sus contenidos en tiempo real. Sin embargo, para Chatfield, no todo es color de rosa, argumentando que la nueva cultura digital está trayendo consigo una intimidad expuesta y a la vez arreglada. Cada cosa que se hace y se publica pasa por un filtro de aceptación y así los internautas cada vez más se 
sumergen en la paranoia de la popularidad virtual. La soledad y la falta de ingenio ante una sobre estimulación de información, comenzará a mostrar consecuencias en un futuro aún lejano. Por otro lado, Quiroz (2013) toma una posición media y acota que si bien existe una tendencia a creer que la interacción personal se pierde y es reemplazada por la virtual, lo que se da mas bien, es una ampliación de los espacios y formas de interacción, debido a que es parte de la condición social de las personas mantener el contacto y la comunicación por distintas plataformas y soportes. Dicho esto, descarta la posibilidad de que el Internet per sé sea el causante de la desaparición de la interacción social presencial, como tampoco le adjudica ser sinónimo de desarrollo. Mal o bien, Castells cierra planteando la utilidad y un punto medio en el rol del internet en la sociedad del siglo XXI.

Entre los rasgos comunes, encontramos el papel desempeñado por Internet y por la lógica de redes en la construcción de la autonomía social de aquellos actores sociales capaces de articular sus proyectos individuales y colectivos (...) Las personas adoptan las tecnologías a sus necesidades y valores, de forma que sus pautas de comportamiento en la vida cotidiana se reproducen en Internet. (Castells, 2004, p308)

\section{Viajar para vivir y vivir para viajar}

El viajero nato actual, no es un exiliado ni mucho menos un cautivo. La búsqueda de experiencia lo lleva a la exploración tanto externa, por los lugares por los que se mueve, como interna por lo que percibe y las personas que logra conocer. Mejía (2010) hace hincapié en el carácter de iniciación que cobra el viaje para este grupo, al enfrentarse a nuevas situaciones. El ímpetu por encontrar algo en su interior, un deseo de soledad mas no de claustro.

Para muchos resulta inconcebible la idea de tomarse unas vacaciones de un mes y en algunos casos, vacaciones interminables. El segmento a estudiar, opta ciertamente por este estilo de vida, el rechazo por la rutina en un mismo lugar y el planeamiento a largo plazo, así como el amor por el "ahora" y la incertidumbre del momento, son quizás otras de las características de este grupo casi revolucionario.

The socialised life model deems the same happiness goals (e.g. property, car, material goods, in other words, the American Dream) for all and does not cater for those with alternative ambitions. Thus the development of the self is homogenised by the state. 
By leaving their country, lifestyle travellers are creating a new self with new values, one that exists beyond the American production line (...) They are publicly nonconformist deviants who as 'members of a rising class locate the source of largescale frustrations in the social structure and portray an alternative structure which would not, presumably, give rise to frustration of the deserving. (Lo, 2014, p9)

A lo largo de los últimos años, este grupo social ha recibido diferentes nombres, desde viajeros, “mochileros” (O’Reilly, 2005) (tornándose como el más común), hasta "vagabundos" (uno de los primeros términos utilizado por Cohen en 1973 para ligar a este grupo con el movimiento hippie y errante de la década sesentera). En contraposición a esta concepción que ligaba a los viajeros con la vida desordenada y libertina, Sorensen plantea que los viajeros, significarían los posibles cimientos de la sociedad y que los viajes significan espacios de reflexión (vacacional) con intenciones claras e inquebrantables de regresar a la vida normal. (Sorensen, 2003). Años después, en su tesis doctoral, Cohen (2009) replantea la concepción de este grupo, explicando que muchos teóricos al notar que los viajes "mochileros" se convertían en algo así como un fenómeno mainstream, decidieron homogeneizar este grupo social, convirtiéndolo en una sola comunidad, a la que Cohen titula como viajeros de tipo de vida o viajeros natos.

I suggest the less derogative term of 'lifestyle traveller'. As 'travellers', as they commonly self-define themselves (Richards \& Wilson 2003), and as adherents to a lifestyle group marked by repeated and extended temporal commitment to travel, involving its own ideologies, praxes and identities, lifestyle travellers represent an identifiable, yet previously overlooked, corpus for research within the backpacker market. (Cohen, 2009, p.4)

Martin-Cabello (2013) menciona que otras teorías encajan a la subcultura viajera como "relativamente homogénea" en su corriente principal, aunque no deja de mantener peculiaridades asociadas a los colectivos a los que se ha aludido. Richards y Wilson (2005), por otro lado, discuten la homogeneidad de este grupo, alegando que las motivaciones y actitudes son variadas. Sobretodo las reacciones ante la posible clasificación de si mismos en un grupo social con nombre y apellido. La idea de clasificación entre mochilero, viajero o turista resulta más compleja de lo que parece. 
Autores como Maoz (2007), especifican que este tipo de turista rechaza clasificarse como tal y dice buscar un contacto más profundo con la naturaleza o con la población de los países que visita. El rechazo por el termino "turista" es un tema recurrente en todas las investigaciones realizadas sobre este grupo. Tanto Cohen (2010a) como O'Reilly (2005) plantean que con el objetivo de marcar la diferencia entre el término, casi despectivo de "turista" es que nacen tantos títulos como "mochilero" o simplemente "viajero". Richards y Wilson (2005) alegan rotundamente que mientras los viajeros no saben a dónde irán, los turistas no saben dónde han estado. Alimentando esta teoría, Sorensen se apega al factor de comodidad perseguido por el turista, planteando que estos buscan una experiencia más cercana a lo que conocen, en vez de sumergirse realmente en la cultura ajena.

Debido a esta ambigüedad de términos, nos identificamos con la última versión de Cohen (2010a) en la que los titula "viajeros natos o de estilo de vida". Son muchos los autores que intentan aproximarse a lo que sería un común denominador en el comportamiento y forma de vida de este grupo. Sin embargo, a pesar de su heterogeneidad, se pueden encontrar rasgos comunes.

\section{El viaje dentro de un mundo integrado a la virtualidad}

Debido a los avances tecnológicos y a la sociedad global y de redes virtuales dominante en el presente siglo, la aparición de nuevas plataformas orientadas al viaje, no tardarían en llegar. Con el objetivo de facilitar el proceso, otorgando no solo tips de viaje, sino nuevas formas de conocer lugares, personas y realidades. Se puede decir que la nueva generación de viajeros natos provenientes de esta corriente tecnológica conserva el mismo deseo de perderse por el mundo pero el exilio dejó de ser una opción. Al reventar la burbuja romántica del viaje, debido a la existencia de una fina línea entre esta idílica concepción de viajar y "perderse" y lo que se vive realmente. En la mayoría de casos la idea del "riesgo seguro" o "borde controlado". La ambigüedad en el discurso de este grupo social, se presenta, precisamente, tras la aparición y casi dependencia hacia la tecnología.

Studies of backpackers online habits, suggest that they have the hours and resources to devote significant amount of time to social networking sites. (Olson, 2008, p13)

El abordaje de la conexión durante el viaje, parte de la idea que se presenta en estudios, vinculando al viajero y al ímpetu por la total desconexión durante el viaje. Sorensen (2003), afirma que entrar a diario al correo electrónico, es un hábito arraigado y las guías para viajeros siempre incluyen en sus mapas, sitios donde conseguir internet. De esta forma se 
evidencia su importancia. Estudios relacionados, los llaman flashpackers y alegan que además de darle importancia a la localización de sitios con internet, los viajeros actuales, nunca prescinden de bienes tecnológicos, como celulares o cámaras digitales.

Si bien autores como Ooi (2002), plantean que los viajeros prefieren verse como personas que persiguen la autenticidad y experimentar aspectos no corrompidos de la sociedad anfitriona. Richards y Wilson (2004) contradicen alegando que la consulta en paginas web vinculadas y plataformas sociales de viaje es bastante recurrente en este grupo. Ellos explican que los principales motivos de viaje son los de exploración y experimentación de nuevas cosas, entre ellas, poder conocer gente como ellos. Visto de esta forma, existe la necesidad de permanecer conectado con el mundo que va formando y que tiene en casa. Olson (2008), termina de explicar la existencia de esta necesidad de estar conectado, sea por mantener contacto con personas, relatar su viaje, leer a otros viajeros o incluso conocerlos. Esta utópica idea de conocer una comunidad de personas como ellos, es un deseo común en los viajeros de hoy en día. De esta forma plantea que las plataformas sociales que les permitan interactuar y hasta plantearse metas con personas aun desconocidas al otro lado del planeta, aporta un valor agregado que los viajeros contemporáneos encuentran imprescindible.

\section{METODOLOGÍA DEL ESTUDIO}

En la presente investigación se planteó una hipótesis general y dos específicas, en concordancia con los objetivos de nuestra investigación.

\begin{tabular}{|c|c|}
\hline \multicolumn{2}{|c|}{ Hipótesis general } \\
\hline \multicolumn{2}{|c|}{$\begin{array}{l}\text { Las tecnologías han afectado y transformado la forma en la que el grupo a estudiar, viajeros de } \\
\text { estilo de vida, perciben y ejecutan sus viajes, permitiendo experiencias de mayor intercambio } \\
\text { cultural y social y facilitando encuentros con personas similares en ambientes propicios y a la } \\
\text { vez manteniéndolos conectados al mundo que ya conocen (se denominará "cable a tierra"). }\end{array}$} \\
\hline \multicolumn{2}{|c|}{ Hipótesis Específicas } \\
\hline $\begin{array}{l}\text { El viaje de estilo de vida es una expresión de } \\
\text { protesta frente a la sociedad capitalista y las } \\
\text { nociones de éxito y realización personal } \\
\text { impuestas. Sin embargo, esta protesta va de la } \\
\text { mano con su condición de usuario activo del } \\
\text { mundo virtual. }\end{array}$ & $\begin{array}{l}\text { El viajero necesita estar conectado para no } \\
\text { perder la orientación en su viaje. Parte del } \\
\text { coraje para viajar, hoy en día, lo propicia el } \\
\text { hilo de conexión de identificación con los } \\
\text { pares, impartido por plataformas virtuales. }\end{array}$ \\
\hline
\end{tabular}


La metodología utilizada en la realización de este estudio fue cualitativa. Se recurrió a un previo análisis documental y bibliográfico de fuentes académicas recientes, revisión de plataformas vinculadas al viaje mencionadas a lo largo de la investigación y de entrevistas a profundidad.

En segundo lugar, se revisaron las plataformas vinculadas al viaje de larga estancia para poder entender sus atributos y el perfil de viajero que buscan con sus servicios.

1. Lonely Planet y Trip Advisor formaron el primer grupo, siendo las representantes más importantes en lo que vincula la información de destinos relevante o útil para un viajero. Lonely Planet, es también conocida como la biblia viajera, tanto en su versión impresa como en su versión virtual.

2. Los blogs de viaje como expresión y nueva guía de información para el viajero. La aparición de estas plataformas y la cercanía que generan con el público que tienen, otorga una nueva opción para buscar información sobre viajes. Estos espacios son tan cercanos y están tan enfocados en la empatía con otros viajeros que explican desde como hacer una maleta y procesos de visado hasta como llegar a parajes no turísticos e inmersos en culturas que podrían ser de interés para viajeros no convencionales.

3. Blabla Car y Car pooling formaron el grupo vinculado a plataformas hechas para facilitar el transporte. Ambas tienen como fin, ser un espacio en el que puedan conectar gente que quiera viajar de manera económica, compartiendo auto (viaje por carretera) con otras personas y pagando los gastos comunes (gasolina) entre todos.

4. Couchsurfing toma el cuarto lugar, siendo una opción altamente conocida por el grupo a estudiar. Esta plataforma tiene como objetivo conectar viajeros con personas locales que quieran dar morada por unas cuantas noches. La característica gratuita de este espacio y del hospedaje en sí, es el mayor hito de este estilo de viaje basado en lazos de confianza.

5. Wwoof, Helpex y Work away hacen que la idea de viajar trabajando en cada destino al que se va, se hace posible gracias a estas plataformas, las cuales generan el vínculo entre empleador y viajero de una forma sencilla y directa. Las opciones de trabajo van desde trabajo físico en granjas eco amigables (Wwoof), trabajo social en ONGs (Helpex) hasta ofertas de trabajo en Hostels y diferentes tipos de instituciones vinculadas al turismo y educación. Todos las ofertas, así sean remuneradas o no, ofrecen alimento y hospedaje gratuito durante el tiempo de trabajo. 
Finalmente, se realizaron treinta y tres entrevistas a profundidad a personas de América y Europa con el perfil estándar de viajero nato. Debido a la búsqueda de un punto de saturación que brindara mayor claridad en patrones comunes y se realizó un muestreo por selección, debido al carácter específico del universo (Mejía, 2000). Se buscó distintos exponentes de sub clasificaciones dentro del gran colectivo de viajeros natos. Treinta de las entrevistas fueron escogidas para transcripción debido a problemas técnicos con las tres restantes, sin embargo, éstas aportaron de igual manera en la resolución de los resultados y hallazgos de la presente investigación. Un tercio de estas entrevistas fueron realizadas en ingles y el resto en español. Se buscó delimitar de manera media a la muestra por lo que las personas entrevistadas son hombres y mujeres entre las edades de 20 y 45 años. Todos ellos con viajes superiores a las tres semanas y con un estilo de vida en la que el viaje es una de las prioridades. Las entrevistas fueron realizadas en un $95 \%$ por skype y un 5\% presencial debido al carácter internacional de la muestra. La media de duración por entrevista fue de una hora. Las nacionalidades incluidas en la investigación son Perú, Argentina, Brasil, Chile, Colombia, Venezuela, Estados Unidos, Canadá, Suecia, Holanda, Bélgica, Portugal, España y Francia. Dentro de la muestra se entrevistaron a cinco blogueros de viaje, un fotógrafo de viaje y una instagramer también orientada a viajes. La variedad entre los perfiles entrevistados fue de suma importancia al momento de la búsqueda y altamente gratificante al lograr los resultados. Las entrevistas se realizaron en Perú e Inglaterra desde junio hasta agosto del 2015. Las entrevistas han sido grabadas en audio, transcritas y traducidas (de ser en inglés) y se adjuntan a la investigación como anexos referenciales.

\section{RESULTADOS}

Tal y como se explicó anteriormente, son muchos los autores abocados a definir e interpretar a este grupo social y su estilo de vida. Se encuentra una comunidad heterogénea pero con ciertas características comunes como la costumbre por cambiar de contextos y la exploración como motivación principal. Así como el deseo por vivir el instante, apoyándose en la incertidumbre del ahora y perdiendo la capacidad de proyectarse. Con respecto a su conexión con la virtualidad, se nota una cierta dependencia mediante la creación de espacios personales en la misma. En el presente estudio, se percibe un hincapié en su singularidad rechazando ser calificados de turistas. Creen que el viaje y el escape pueden ser términos que se conecten pero prefieren entenderlo como una búsqueda a todo nivel. Existe un miedo a la desconexión, para lo cual las plataformas para viajeros resultan muy útiles, sin embargo, su uso es circunstancial e ingrato. Esto se concluye, luego de encontrar un patrón de respuesta en las 
treinta y tres entrevistas realizadas, formando un perfil del viajero y su conexión con el mundo virtual al momento del viaje.

\section{Pasaporte al mundo del viajero}

Luego de realizar las treinta y tres entrevistas a profundidad, se hallaron patrones de respuesta vinculados en primera instancia a demarcar el perfil del viajero nato. Con esto, definir las verdaderas motivaciones detrás del viaje por periodos más largos de tres semanas, entender el proceso, nociones de vida, realización personal y del mismo concepto de viaje que tiene este grupo social al ser parte de una realidad virtualmente conectada.

El viaje largo se encuentra ligado de manera inquebrantable al deseo de independencia y libertad. La construcción de uno mismo, mediante la adecuación a nuevos espacios, es algo que aporta de manera indudable al viajero, así como la búsqueda de emociones fuertes, experiencias nuevas y sobretodo diferentes. Los viajeros especifican que sienten como si "perdieran el tiempo" cuando no están viajando. El hartazgo de la rutina y de hacer lo mismo cada día, mientras frecuentan a las misma personas, lleva a una saturación tal, que el punto de quiebre resulta el viaje mismo. Así mismo, especifican que hay tiempo para todo y que aún así, una de sus principales prioridades sea viajar, saben y creen firmemente que pueden establecerse y hasta formar una familia cuándo y dónde lo deseen.

Me gusta conocer nuevas formas de pensar para poderme construirme a mí misma, sin dejar de ser yo misma, mi nacionalidad y mi propia cultura. Además, siento que no puedo estar en el mismo lugar por tanto tiempo porque me aburre y necesito nueva gente, gente diferente y bueno, eso sería de alguna manera corta de explicar. (Julie Frobert, 24)

Salir de mi zona de confort, tomar el riesgo fue mi motivación principal para viajar. Para completar mis estudios tenía que viajar obligatoriamente, y estaba cómodo con estar incómodo, me gustaba la sensación de no saber qué va a pasar. Así que cuando que cuando decidí ir a Sudamérica sólo, con mi mochila, viajar y caminar y ver qué pasa sin un plan, creí que fue hermoso. (Ruben Paganopoulous, 24)

Existe un rechazo a considerarse "turista". Prefieren considerarse viajeros ya que hacen un tipo de viaje "auto gestionado". Expresan que de ninguna manera optan por viajes guiados porque eso no les permite relacionarse con el entorno ni la gente del lugar. Que si bien es importante ir a los lugares "turísticos" de cada ciudad, en muchos casos por su valor 
histórico, es el doble de importante, andar por las calles donde la gente local anda normalmente. Eso es una diferencia notable entre un viajero y turista, para ellos.

No, no me considero un turista porque relaciono esta palabra, con los que hacen los tours, paseos pagados y paquetes de viajes. Yo he elegido en mis tres años de viaje, no hacer ningún tipo de pago por paseos, ni siquiera por museos, con excepción de Louvre en París, que de verdad quise estar ahí (...) Creo que los viajeros mismos intentan conocer la cultura y los sitios de manera distinta. Eso no quiere decir que una esté bien y la otra esté mal; son solamente dos perfiles. Quizá, si me voy a viajar con mi novia y con mis hijos, voy a tener un perfil más de turista. (Thiago Bertho, 33)

Yo siento que soy una persona que va a vivir, que mientras menos conozca del lugar antes de ir, es mejor, porque me sorprendo, me arriesgo (...) No me gusta el tema de hacer lo que todos hacen, hacen las mismas fotos en el mismo árbol y todo. De hecho me gusta mucho la fotografía pero prefiero que todo quede en la memoria. (Sebastián Espinoza, 24)

Se afirma la relación entre viajar y escapar. En muchos casos, si bien cuesta afirmar que se huye de algo, lo relacionan con otra experiencia conocida y la toman como una opción personal. La búsqueda de nuevos espacios con personas en las mismas circunstancias forma un entorno en el que se comparten, además de perspectivas de vida, motores y razones por las cuales estar ahí. Muchos otros prefieren vincular el viaje a la búsqueda en todo nivel, buscan encontrarse, enfrentándose a nuevas experiencias en lugares y contextos desconocidos.

Yo le pregunté “oye y ¿te gustaba la ciudad en la que vivías (al norte de Camboya)?” Ella me dijo que era un hueco de porquería, pero al estar ahí con los otros extranjeros, se volvió en su hueco de porquería y paraba con gente que no conocía mucho pero que sabia que todos escapaban por algo. Todos estaban ahí por algo y juntos se convirtieron en una familia. En ese lugar, por alguna razón, se encontraban más a gusto. Nunca le pregunté de qué escapaba ella, pero me dejó claro que todos huimos de algo en algún momento. Yo, básicamente huía de la rutina, huía sí, básicamente eso. (Enrique Richter, 27)

Todo el mundo podría decir que mi vida se estaba derrumbando cuando decidí irme, pero en verdad, la única forma en la que lo puedo ver es que todo se estaba ordenando (...)Vendí mi casa y compré un boleto a Paris (...)De alguna forma me fui o huí dejándolo todo, para encontrarlo todo durante el viaje. (François Gauthier, 44) 
Consideran que interactuar con gente local y sumergirse en su cultura es básico para conocer realmente el lugar donde están. Ésta es una de las razones por las cuales optan por plataformas como Couchsurfing, Wwoof o Blabla car, para poder conocer las ciudades donde van, desde la perspectiva local y rutinaria. Expresan que la homogeneidad de los hoteles de lujo o los servicios de tour tradicionales, hace que puedas cambiar de destino muchas veces y lo único que va a cambiar es el discurso que te cuentan o la vista que tienes al otro lado de la ventana o del bus. Las ciudades se deben descubrir a paso ligero y observador, por medio del idioma, la comida, las costumbres y la interacción obligatoria con los protagonistas de cada realidad (locales).

Conocer a la gente local es básico, es la única razón de ir, poder comunicarse con ellos. Como por ejemplo cuando estuve haciendo dedo al lado del mar negro en Turquía, hubo gente que nos invitaba a su casa para comer y conocer a su familia. Muchas veces pasan esas cosas y eso es lo que yo quería tener como experiencia, no solo poder decir que vi el mar negro, si no que además de ver toda la costa de Turquía, conocí un montón de gente ahí. (James Lowell, 30)

Yo estoy acá por ejemplo en Bogotá, pero estoy encerrada en un hotel. ¿De qué me cambia a mí? Estar en Bogotá, estar en Buenos Aires, estar en la China, si estoy dentro de cuatro paredes ¡No estoy ahí! El estar en un lugar significa salir, ir a ver, preguntar, probar, eso es estar en un lugar. (Florencia Ferrari, 26)

Por otro lado, para conocer el grado de apego hacia las personas y lugares, se preguntó sobre la noción de hogar. Varios de los viajeros entrevistados expresaron que en algún momento podrían optar por comprar un pasaje sin retorno a cualquier sitio del mundo pero que lo que principalmente, los unía o "ataba" a su lugar de origen era su familia. La palabra "hogar" se relaciona a todo lugar donde se sientan cómodos y bien consigo mismos. No tiene que ver necesariamente con un lugar físico, sino un lazo emocional con las personas con las que se comparte. Destacan no extrañar demasiado sus países, sino a las personas que dejan cuando viajan.

Creo que para mí está relacionada con familia. En realidad es una idea interesante, porque pienso bastante sobre dónde quiero vivir y amo Sudamérica, también amo Suecia, tal vez podría vivir en Australia, pero hogar es dónde están mis padres, mi hermano y mis mejores amigos. Las personas son las que hacen el hogar. (Amanda Powers, 23) 
Hogar, para mí es unas personas muy específicas que son: mis papas y mis hermanos. Pero sí, pero el hogar para mí son estas personas que siempre, pase lo que pase, son gente que siempre me va a querer, que siempre va a estar ahí y en realidad no tengo miedo para nada de perder eso entonces yo sé que puedo viajar por todo el mundo y puedo desaparecerme de repente años y mi hogar siempre va a existir y va a estar ahí. Entonces, no me preocupo por eso. (Brendali Carrillo, 30)

En segundo lugar, la concepción de "éxito" está directamente relacionada a la realización personal y el viaje es parte de esta búsqueda. Si bien, todos reconocen la existencia de un patrón estandarizado de éxito vinculado al campo laboral y profesional, se niegan a sumarlo a sus expectativas de vida. El éxito es un concepto puramente subjetivo basado en lo que hace feliz a cada ser humano. En algunos casos, tiene que ver con sentirse satisfecho con cada día vivido y en otros con su vida en general, como un gran triunfo.

Para mí el éxito sería vivir haciendo lo que amas. Si eso me genera grandes cantidades de dinero o no, no entra en el concepto. Pero lograr una tranquilidad emocional que me permita vivir sin preocupaciones, creo que eso es el éxito para mi (...) El hecho de viajar no te aleja de donde quieres llegar (...) Si te dicen: “¿al final qué consigues?” lo mismo que tu vas a conseguir con un trabajo después de años para mantener a otros para al final disfrutar tu, nosotros cambiamos el orden. Disfrutamos ahora. (Jaime Ramirez, 29)

El éxito para mí es que hayas logrado lo que te propusiste en tu vida. Te quisiste montar al Everest, fuiste y lo hiciste. Para mí ya eres exitoso. Yo me siento exitosa porque siempre quise hacer esto (viajar) y siempre había un "pero". La sociedad me comía viva cuando quería salirme de la raya. Yo ya tuve un buen trabajo, un buen cheque, un buen carro, estudios, etc. pero en un punto decidí salirme de esa raya y por eso me siento exitosa, siento que voy por buen camino. (Andrea Pisani, 26)

\section{¿Conectado(a)?}

Por otro lado, la tecnología y las plataformas vinculadas al viaje les resultan útiles y de alguna manera responden a las necesidades de los viajeros. Los viajeros coinciden en que la tecnología ha facilitado y ayudado mucho en que se pueda viajar de manera mas fácil y barata. Sin embargo, dudan de la premisa en la que se especifica que la tecnología ha hecho del viaje, una opción más segura. Se basan en que definitivamente, la tecnología presenta una enorme gama de opciones (plataformas) para que el viajero sea (o se sienta) más independiente y no tenga que depender de terceros al momento de decidir viajar. Sin embargo, el riesgo siempre existe, más allá de que lean múltiples experiencias positivas y recomendaciones de algún lugar.

La tecnología hizo que vivir y viajar se vuelva más fácil (...) Las plataformas hacen que la experiencia de viaje sea más flexible, encuentras lugares más económicos, conoces 
personas, definitivamente lo hace más sencillo. No sé si las páginas web hacen que el viaje sea más seguro porque te permite puedes conocer personas en otros países y tener la certeza de que nada que va a pasar, el internet te hace confiar más en ese sentido. (Cecile Blayac, 29)

Primero, de cierta manera todo este boom tecnológico ha permitido facilitar mucho más todo el tema de viajes. Existen aplicaciones para que alguien se hospede, poder conseguir "tiquetes", hace mucho más rápido el hecho de viajar y permite mantener una constante comunicación con tus allegados. Ciertamente también ha sido una manera de contribuir a que haya más viajes. Siempre alguien llega a un sitio, toma una foto y el resto del mundo la ve y dice “¡Ay! Yo quiero ir a ese sitio”. Se comparten experiencias y se incentiva a que más personas lo hagan. Para mí ha sido muy positivo todo eso. (Juan Pablo Morales, 23)

Por otro lado, con respecto a las plataformas de viaje, sostienen si bien, son altamente útiles, la consulta en las mismas es solo al momento de pensar en un viaje, mas durante otros periodos es puramente circunstancial. Intentan desligarse de su utilidad, alegando lo increíble que sería volver a la forma casi nómade en la que viajaban los viajeros del siglo XX. Sin embargo, resaltan que no les sería posible hoy en día.

Hay tanto control del otro que ya es difícil desprenderse y la idea del viaje era que uno se iba a la nada y se iba recontra lejos en otro país (...) Ahora tenemos wifi, skype, la oportunidad de vernos las caras, todo eso. Podrías apagar el teléfono, tirarlo y olvidarte. Pero el hecho de tenerlo, que además de por sí ya es una utilidad, en el día a día, como que no te permite desconectarte tanto. (Paula Orlando, 23)

Digamos, hay un montón de soportes que te dan la mano, de hecho, nuestro viaje se estructuró con tablets en la mano para ver a dónde íbamos, ver el mapa en Google y decidir la ruta, los kilómetros; además de buscar en internet que había para ver o por donde podíamos ir o por donde no. El couchsurfing, foros de diferentes lugares y bueno, ni hablar del Facebook y la posibilidad de comunicarnos. Puedes agarrar las mil y una pero bueno, en internet más o menos te servía de guía. Así que fue un complemento importantísimo antes de viajar y también durante el viaje. (Ignacio Cichello, 27)

La fidelidad hacia con los blogs es imperceptible. Los buscan con objetivos específicos y dentro de una búsqueda general. Valoran su existencia y el hecho de que sea más cercano y personal. En algunos casos, sirve de inspiración o motivación para seguir 
viajando, arriesgarse a hacer nuevas rutas o conocer nuevas plataformas que los ayude durante el viaje. Sin embargo, en pocos casos existe un seguimiento mediana o realmente marcado a algún blog específico.

Leo algunos y he leído algunos pero no sabría decir ni un solo nombre. Me gusta porque al final te cuenta una experiencia muy directa y yo lo veo muy útil. (Santiago Fernandez, 30)

Siempre es una ayuda, pero a la vez es una fuente de inspiración porque yo he hecho muchos viajes a sitios que a lo mejor nunca me hubiera imaginado porque lo he leído en un blog. Los blogs al final son prescriptores de los viajes en sí, o sea nos retroalimentamos unos a otros y nos ayudamos también. A mí me parece que en muchas cosas te facilita la vida y que te puedes ayudar a muchos niveles. $\mathrm{O}$ sea que creo que es bueno y pues son las guía del viajero hoy en día, pues a mí me ha salvado el culo varias veces. (Patricia Rojas, 36)

Alegan que el verdadero objetivo del viaje es poder estar desconectado más no saben si hoy en día, pueden estar verdaderamente desconectados. El apego parece ser por la "familia". Existe un rechazo a decir que la tecnología es imprescindible. Nuevamente, se hace presente el ímpetu romántico de poder volver al viaje del nómade bordeando el exilio, la contradicción se encuentra al momento de preguntar por la tecnología. La posesión de smartphones, cámaras digitales, computadores portátiles, entre otros, denotan un apego que yace inconsciente en la mente de varios viajeros.

Yo creo que como marco es muy difícil estar desconectado estés donde estés hoy en día, muy difícil. Una cosa como que ahora tienes que estar conectado, una cosa como que ahora tienes que esforzarte para no estar conectado, antes tenías que esforzarte para conectarte, ahora tienes que esforzarte de verdad para no estar conectado. (Rodrigo Bustamante, 27)

Creo que las redes pueden ser una ayuda pero también como un ancla a tu ciudad que te impide escapar. Cuando estaba viajando a Asia no tuve internet y fue lo mejor del mundo. (Gabriela Marín, 24)

Finalmente, los viajeros afirman que las plataformas de viaje y la "viralización de viaje" en si misma, sirve de estímulo para que más gente viaje. Claro está que este efecto se da en personas con este perfil específico y en muchos casos ahuyenta el miedo y termina siendo el punto de quiebre para que estas personas se decidan a optar por este estilo de vida. 
Bueno si, por ejemplo el Instagram ha ayudado a personas que no conocían nada a que conozcan una cosa y poder viajar para ese lugar, como realizar ese sueño que antes no podían ni imaginar que es ese lugar. Muchos preguntan, mucha gente manda mensajes, que no saben nada de nada "ayúdame”, "a dónde puedo ir. (Monique Miranda, 30)

Queremos que la gente vea que viajar no es imposible. Conocemos a mucha gente que comenzó a viajar porque se inspiraron en nosotros. La gente comienza a descubrir que hay otros lugar para visitar aparte de Miami y Paris. Las personas en general piensan en ir a Europa y Estados Unidos. Nuestro próximo país a visitar es Irán y muchas personas nos dicen que estamos locos porque creen que estamos yendo a un país en guerra, pero no es así. Se sorprenden al ver las fotos de los países que nunca visitarían. (Gabriela Moniz, 32: Fabricio Faria, 38)

\section{DISCUSIÓN}

Para comenzar a especificar los hallazgos de esta investigación, se debe partir explicando el grupo demográfico al que se investigó. Cimentando el estudio en la clasificación que Cohen (2009) le otorga a esta comunidad, "viajeros de estilo de vida", se dejaron de lado, toda especie de subgrupos que tenían su razón de ser en formas especificas de viaje como el consumo, preferencias durante el viaje y destinos, para enfocarnos en el viajero per sé. Aquella persona con el famoso "travel bug” o "bicho viajero".

El estudio realizado, partió de diversas teorías en las que explican la identidad nómade del viajero, haciendo hincapié en características ya mencionadas como el cambio y el rechazo a ser una comunidad homogénea. El presente estudio, discute el planteamiento homogéneo de Martin-Cabello (2013), como el heterogéneo de Richards y Wilson (2005), encontrando un punto medio. Se desmitifica la necesidad de enfrascar al grupo en pequeños sub grupos, encontrando características globales suficientes para plantearlos como un grupo de singularidades.

La opción de viajar nace al vincularse directamente a conceptos de felicidad, autorrealización, curiosidad, búsqueda y hasta aburrimiento de la vida misma (rutina). Este carácter cambiante, curioso y decidido en lo que quiere, es lo que rige a este grupo. La percepción de destiempo, sensación de incertidumbre, junto con el continuo in crescendo de emociones, es sin duda alguna, lo que hace que el viaje se vuelva la alternativa a escoger. En 
la medida en que estos indicadores sean más o menos marcados es que se pueden hallar diferenciaciones.

Tal y como plantean Richards y Wilson (2005), tras describir la complejidad de colocar un rótulo a este grupo, se pudo captar que el rechazo a ser considerado turista resulta una característica mayoritaria, por lo que colocar un nombre se basa en la búsqueda de características globales y repetitivas en la muestra. La estigmatización del término se hace presente, pese a que la mayoría desconoce su verdadero significado. Adquiere tanta importancia que si bien no saben que rotulo utilizar para definirse, claro esta que marcan su distancia con el viaje de tipo turista, destacando la singularidad de su experiencia de viaje en comparación a la del resto. Reafirmando de esta manera lo propuesto por Cohen (2010a) y O’Reilly (2005) con respecto a la búsqueda de diferenciación con el universo de viajeros. Además, la conexión entre el viaje y el escape fue un tema reafirmado durante este estudio, alegando que si bien autores como Cohen (2010b) y Mejia (2010) plantean una relación directa en ambos términos, durante el presente estudio se pudo descubrir una arista un tanto más optimista, en la que se tocaba el viaje como una búsqueda a todo nivel mas que como una evasión. Se puede deducir que el impulso hacia un viaje largo tiene que ver directamente con el hartazgo hacia el lugar de origen, creando la "necesidad" en muchos de los casos, de cambiar radicalmente de contexto. Existe una finísima línea entre huir llevando la mochila cargada de preocupaciones y salir en la búsqueda de nuevos espacios para solucionar esas preocupaciones. Por otro lado, si bien se explica que se dejaron de lado clasificaciones específicas de viajero, se pudieron encontrar rasgos comunes en cuanto a la experimentación durante el viaje. Tal y como plantea Maoz (2007) en una búsqueda más profunda por mimetizarse con los lugares visitados. El interés por vincularse con gente local sobrepasa cualquier otra prioridad y hasta ocupa un lugar central en el propósito del viaje. Junto con esta, destacaron la importancia de aproximarse a la comida, al idioma y a la rutina diaria del destino visitado.

Saliendo de lo planteado por los autores ya mencionados, se decidió empujar hacia los límites con preguntas vinculadas al "éxito" y al "apego", para determinar un perfil que se enfrente al común denominador de los agentes encontrados en la sociedad, buscando rutas alternas a los "ya conocidos términos". Sin duda, ambas interrogantes dieron pie al entendimiento más profundo de su estilo de vida. Destacaron la importancia de las emociones y las relaciones familiares e interpersonales, sobre el vínculo con lo material y espacial. Los cinco puntos expuestos con relación 
al perfil del viajero nato, esclarecen una idea general de motivaciones, concepciones y formas de viaje, retroalimentándose unos a otros.

Finalmente con respecto a la conectividad, se partió de lo mencionado por Sorensen (2003) con respecto a la característica rutinaria que tiene el uso del internet y artículos digitales durante el viaje. Sin embargo, el mayor aporte de la investigación y el que significó un mayor reto, va de la mano con la presencia de la tecnología y la necesidad hacia con la misma. Acotando a lo explicado por Ooi (2002), los viajeros dejaron claro el interés por desprenderse del mundo "conocido" durante el viaje para entregarse a la experiencia. Hasta se podría decir que pintan el viaje como una expresión de protesta frente a la sociedad capitalista y las nociones de éxito y realización personal impuestas. Sin embargo, esta protesta va de la mano con su condición de usuario activo del mundo virtual. Siguiendo con lo planteado por Olson (2008), resaltaron la utilidad de la tecnología y las plataformas virtuales durante el desarrollo de su travesía. Parecía requerirse mucho esfuerzo para recordar como podría haber sido el viaje sin las facilidades tecnológicas del presente, tanto a nivel de comunicación, como podrían ser las plataformas sociales (Mail, Skype, Facebook, etc) como a nivel informativo, como son las plataformas específicamente orientadas al viaje (Lonely Planet, Couch surfing, Blabla Car, Wwoof, Blogs de viaje, etc). Sin embargo, como punto de quiebre con las teorías anteriormente mencionadas, se descubrió que la fidelidad virtual no es una característica que describa a este grupo. Ven la tecnología como algo importante y sumamente útil, mas no les interesa pasar más tiempo del necesario utilizándolas mientras viajan. La aparición de blogs de viajes y otro tipo de plataformas que brindan información de primera mano, se han vuelto algo así como una parada imperdible al momento de buscar información, sin embargo, una vez recolectado lo que se necesita, no se vuelve a conectar.

El viajero necesita estar conectado para no perder la orientación en su viaje. Parte del coraje para viajar, hoy en día, lo propicia el hilo de conexión de identificación con los pares, impartido por plataformas virtuales. Puesto que si bien existe un total deseo por vivir de las experiencias y nutrirse de nuevas culturas, mimetizándose en la medida de lo posible en ellas, el miedo a la desconexión y la posible "soledad" del viaje, genera una contradicción. La aparición de plataformas específicamente para viajes, proporcionan al viajero de distintas herramientas para socializar, conseguir hospedaje, transporte, trabajo y hasta alimento. Una persona que lucha por liberarse de los estigmas de posicionamiento social pero que no pierde el cable a tierra. 
El carácter transitorio de la era en la que nos encontramos deja una cuota de ambigüedad para esclarecer del todo, el rol de la tecnología. En un futuro, sería mas exacta la tendencia en este colectivo. Dicho esto, la comunidad a estudiar se perfila como un grupo con proyección a multiplicarse en los próximos años. Estudios que desglosen diferentes aspectos y concepciones de la sociedad como los roles específicos de cada plataforma y el discurso que traen por detrás, serían de completa utilidad para seguir conociendo a este fascinante grupo humano. Se requieren estudios más específicos y para eso se necesita un grupo más grande y sólido. Si seguimos lo recogido en esta investigación, la tecnología, el ímpetu por independizarse y la viralización del viaje per sé, comenzarán a dar frutos para futuras investigaciones. 


\section{REFERENCIAS}

Castells, M. (2001) La era de la información. Economía, sociedad y cultura. Fin del Milenio (Vol. III) (3 ${ }^{\mathrm{a}}$ ed.). México D.F, México: Siglo XXI Editores S.A

Castells, M. (2004) ) La sociedad red: una visión Global (1ª ed.). Madrid, España: Alianza Editorial S.A.

Chatfield, T. (2012) Cómo prosperar en la Era Digital (1 ${ }^{\mathrm{a}}$ ed.). Barcelona, España: Ediciones B S.A.

Cohen, S. (2009). The search for "self" for lifestyle travellers (Phd Thesis). Univerity of Otago. Otago, Nueva Zelanda. Recuperada de https://www.academia.edu/697127/The_search_for_self_for_lifestyle_travellers

Cohen, S. (2010a). Personal identity (de)formation among lifestyle travellers: A double-edged sword?. Leisure Studies, 29(3): 289-301. DOI:10.1080/02614360903434100

Cohen, S. (2010b). Searching for escape, authenticity and identity: Experiences of lifestyle travellers"e. En M. Morgan, P. Lugosi \& J.R.B Ritchie (Comps.), The Tourism and Leisure Experience: Consumer and Managerial Perspectives (pp. 27-42). Channel View Publications. Bristol, Inglaterra.

Dobbs, D. (Enero 2013). Restless Genes. National Geographic. Recuperado de http://ngm.nationalgeographic.com/2013/01/125-restless-genes/dobbs-text.

Lo, G. (2014). Lifestyle travellers and self-development. (MSc thesis) University of Oxford, Oxford, Inglaterra. Recuperada de https://www.academia.edu/8596124/Lifestyle_travellers_and_self-development

Maoz, D. (2007). Backpackers motivations: The role of culture and nationality. Annals of tourism Research, 34(1):122-140. DOI: 10.1016/j.annals.2006.07.008.

Martin-Cabello, A. (2013). El turismo backpacker en Chile como expresión de una subcultur juvenil global. (Tesis de licenciatura) Universidad Rey Juan Carlos, Madrid, España. Recuperada de http://dialnet.unirioja.es/servlet/autor?codigo322991'

Mateus, J.C (2010) Jóvenes y Política 2.0: ¿Del desencanto real al oportunismo virtual? Contratexto Digital. N18. ISSN 1993-4904. Recuperado de 
https://www.academia.edu/996238/J\%C3\%B3venes_y_pol\%C3\%ADtica_2.0_Del_desencant o_real_al_oportunismo_virtual

Mejia, M. C. (2010). Intercambio de Piel. (Tesis de Licenciatura) Universidad de Girona, Girona, España. $\quad$ Recuperada de http://www.lanimal.org/image/memoria/181/pdf/100610-181-8.pdf

Mejia, J. (2000) El Muestreo de la Investigacion Cualitativa. Investigaciones Sociales, 4(5), 165-180.

Quiroz, M.T (2013) Sin Muros. Aprendizajes de la Era Digital. (1ra ed.). Lima, Perú. Universidad de Lima Fondo Editorial.

O'Reilly, C. (2005). Tourist or traveller? Narrating backpacker identity. En A. Jaworsky, \& A. Pritchard (Comps.) Discourse, Communication and Tourism. Gran Bretaña. Recurperado de http://bit.ly/1KphS1n

Olson, T. (2008) Introducing Wanderlust: Proposing and defending the utility of a social networking space for contemporary backpackers. (Master thesis) New York University Tisch School of Arts, Nueva York, Estados Unidos Recuperada de https://www.yumpu.com/en/document/view/21704171/new-york-university-tisch-school-ofthe-arts-

Ooi, C-S. (2002) Attention and the Construction of Tourism Experiences (Phd Thesis) Copenhagen Bussiness School. Fredericksberg, Dinamarca. Recuperada de https://www.academia.edu/3051982/Attention_and_the_Construction_of_Tourism_Experienc $\underline{\text { es }}$

Richards, G., \& Wilson, J. (2004). The Global Nomad: Backpacker travel in theory and practice. (Cap.1) Multilingual/Matters Lpd. Gran Bretaña. Recuperado de https://www.academia.edu/1272257/The_global_nomad_backpacker_travel_in_theory_and_p $\underline{\text { ractice }}$

Richards, G., \& Wilson, J. (2005). Backpacker tourism: The contemporary face of $\begin{array}{llll}\text { youth } & \text { tourism. } & \text { Recuperado }\end{array}$ https://www.academia.edu/2283945/Backpacker_tourism_the_contemporary_face_of_youth_ $\underline{\text { tourism }}$ 
Sorensen, A. (2003). Backpacker etnography. Annals of tourism research, 30(4):847867. Doi: 10.1016/S0160-7383(03)00063-X

Villanueva, E. (2010) Vida Digital: la tecnología en el centro de lo cotidiano ( $1^{\mathrm{a}}$ ed.). Lima, Perú: Fondo Editorial PUCP.

Plataformas virtuales de viaje:

- Trip Advisor

https://www.tripadvisor.com.pe/

- Lonely Planet

http://www.lonelyplanet.com/

- Blabla Car

https://www.blablacar.es/

- Car Pooling

http://www.carpooling.co.uk/

- Couch Surfing

https://www.couchsurfing.com/

- Helpx

https://www.helpx.net/

- Wwoof

http://www.wwoof.net/

- Work Away

https://www.workaway.info/

Blogs

- Walking Around - Fabio Inacio 
http://www.walkingaroundph.com/

- Projeto 101 Paises - Gabriela Moniz y Fabricio Farias.

http://www.projeto101paises.com.br/

- Viajando Sin Papel Higienico - Daniel Tirado

http://viajandosinpapelhigienico.com/

- Mochilao Trips - Carol Moreno

http://mochilaotrips.com/

- La Peca Viajera - Andrea Pisani

http://thetravellingfreckle.org/

- La Cosmopolilla - Patricia Rojas

http://lacosmopolilla.com/ 